九州大学学術情報リポジトリ

Kyushu University Institutional Repository

\title{
Structures of Sialooligosaccharides Obtained by the Acetolysis of Whale Cartilage Keratosulfate
}

Nakagawa, Hiroki

Laboratory of Fisheries Technology, Faculty of Agriculture, Kyushu University

Satake, Kuniko

Laboratory of Fisheries Technology, Faculty of Agriculture, Kyushu University

https://doi.org/10.5109/22820

出版情報：九州大学大学院農学研究院紀要. 17 (1)，pp.75-98，1972-08. Kyushu University バージョン：

権利関係 : 


\title{
Structures of Sialooligosaccharides Obtained by the Acetolysis of Whale Cartilage Keratosulfate
}

\author{
Hiroki Nakagawa and Kuniko Satake \\ Laboratory of Fisheries Technology, Faculty of Agriculture, \\ Kyushu University, Fukuoka
}

(Received December 5, 1971)

\begin{abstract}
To establish the structure of the nonreducing region of whale cartilage keratosulfate, sialooligosaccharides were isolated from the acetolysis products of the keratosulfate, and their structures were studied. The keratosulfate was subjected to acetolysis followed by fractionation of the resulting products, and six oligosaccharides were isolated. The structures of two sialooligosaccharides and a major disaccharide among the oligosaccharides were investigated by reducing end analysis, sequential hydrolysis with specific glycosidases and periodate oxidation, and the following structures were proposed for them : N-acetylneuraminyl- $(2 \rightarrow 3)-\beta-\mathrm{D}$-galactopyranose, $\mathrm{N}$-acetylneuraminyl-(2-3)- $\beta$-D-galactopyranosyl-(1 $\rightarrow 4)-2$-acetamido-2-deoxy- $\beta$-D-glucopyranosyl-(1 $\rightarrow 3)$ $\beta$-D-galactopyranose, and 2-acetamido-2-deoxy- $\beta$-D-glucopyranosyl-(1-3)- $\beta$-D-galactopyranose. Considering these results along with the carbohydrate composition and molecular weight of the keratosulfate, the authors presumed that about four $\mathrm{N}$-acetylneuraminyl-galactosyl-N-acetylglucosamine units were linked to the internal portion of the carbohydrate chain of the keratosulfate.
\end{abstract}

\section{INTRODUCTION}

Keratosulfate, which is thought to have the repeating units of $\mathrm{N}$-acetyllactosamine polymerized through 1-\&linkages to galactose and to contain more than 1 mole of sulfate per unit, is the most ambiguous of acid mucopolysaccharides from connective tissues.

Two different keratosulfates, one from cornea (Meyer et al., 1953) and the other from cartilage (Mathews and Cifonelli, 1965; Seno et al., 1965), have been known. The structures of keratosulfates from bovine cornea (Hirano et al., 1961; Bhavanandan and Meyer, 1967) and old human rib cartilage (Bhavanandan and Meyer, 1968) have been investigated mainly by the methylation technique, and the basic structures of them are believed to be similar. However, it appears that cartilage keratosulfate has higher contents of minor components such as galactosamine, mannose, sialic acid and fucose, smaller molecular size, and a greater degree of branching than cornea1 keratosulfate.

Keratosulfate from nasal cartilage of a whale contained a large amount of sialic acid (N-acetylneuraminic acid) (Nakagawa and Satake, 1971; Toda and Seno, 1970), and its chemical composition and molecular size were very similar to keratosulfate-like mucopolysaccharides isolated from chick allantoic fluid (Meyer 
et al., 1967), and from liver (Callahan and Wolfe, 1970; Suzuki et al., 1969) and urine (Wolfe et al., 1970) of patients with $\mathrm{G}_{\mathrm{MI}}$-gangliosidosis. In order to clarify the ambiguous parts of the keratosulfate structure, the authors have investigated the detailed structure of whale cartilage keratosulfate (WKS).

The ketosidic bond of sialic acid appears to be fairly resistant to acetolysis (Kuhn and Wiegandt, 1963), though it is very weak to acid hydrolysis. Therefore, the authors undertook to obtain sialic acid-containing oligosaccharides (sialooligosaccharides) by the acetolysis of WKS, and to establish their structures. This paper describes the acetolysis of WKS, isolation and purification of sialooligosaccharides, and structures of them.

\section{EXPERIMENTAL}

\section{Preparation of WKS}

Nasal cartilage of a sei whale (Balaenoptera borealis) which had been stored at $-25^{\circ} \mathrm{C}$ was freed from adhering connective tissue, finely chopped, and washed with water. One kilogram of the chopped cartilage was suspended in 1 liter of water, and heated with continuous stirring to $60^{\circ} \mathrm{C}$. To this were added $7 \mathrm{~g}$ of calcium acetate monohydrate and $1 \mathrm{~g}$ of Pronase (Grade P, Kaken Kagaku Co., Ltd., Tokyo), the pH was adjusted to 8.0 with $\mathrm{NaOH}$, and the mixture was stirred at $60^{\circ} \mathrm{C}$ until the cartilage was liquefied. One gram of Pronase was again added, the $\mathrm{pH}$ was readjusted to 8.0 , and the mixture was incubated at $37^{\circ} \mathrm{C}$ for $48 \mathrm{hr}$ in the presence of toluene. The digest was filtered through a Celite pad on a Buchner funnel. To the filtrate, sodium acetate was added to give a concentration of $5 \%$, the $\mathrm{pH}$ was brought to 5.0 with glacial acetic acid, and ethanol was added to give a concentration of $40 \%(\mathrm{v} / \mathrm{v})$. After being left at $5^{\circ} \mathrm{C}$ overnight, the mixture was centrifuged. To the supernatant, ethanol was again added to give a concentration of $60 \%$, and after several hours the mixture was centrifuged. In the supernatant obtained, more than half of the sialic acid present in the cartilage was found. The supernatant was concentrated below $40^{\circ} \mathrm{C}$ to a small volume in a vacuum rotator, and dialyzed against running tap water, then against deionized water by the use of Visking cellulose tubing (type C-65). The bag contents were concentrated to about $200 \mathrm{ml}, 1.8 \mathrm{~g}$ of calcium acetate monohydrate, $0.4 \mathrm{~g}$ of Pronase and $10 \mathrm{ml}$ of ethanol were added, and the mixture was adjusted to $\mathrm{pH} 8.0$ with $\mathrm{NaOH}$, followed by incubation at $37^{\circ} \mathrm{C}$ for $72 \mathrm{hr}$. The incubation mixture was brought to $\mathrm{pH} 5.0$ with glacial acetic acid, and repeatedly deproteinized by the Sevag method (Staub, 1965). The deproteinized aqueous layer was passed through a column $(2.7 \times 35 \mathrm{~cm})$ of Dowex $50-\mathrm{X} 2$ (200-400 mesh, $\mathrm{H}^{+}$) in the cold for complete removal of free peptides. The effluent and washings were collected into a flask cooled in an ice bath, and neutralized with $\mathrm{NaOH}$ within 20 min to avoid acid hydrolysis of the sialic acid linkage of WKS. The neutralized solution $(400 \mathrm{ml})$ was applied to a column $(3.0 \times 80 \mathrm{~cm})$ of Dowex 1-X2(200-400 mesh, Cl-), and the column was washed with water until the washings gave a negative anthrone test, WKS adsorbed on the column was then eluted with a linear gradient of $\mathrm{NaCl}$, starting with 1.51 of water in the mixing flask and 1.51 of $3 \mathrm{M} \mathrm{NaCl}$ in the reservoir. Most of WKS was eluted with 0.4-1. $0 \mathrm{M} \mathrm{NaCl}$. The WKS fraction was concentrated, desalted on Sephadex 
G-25, and lyophilized, yielding $1.7 \mathrm{~g}$. This preparation gave a similar infrared spectrum to that of bovine cornea1 keratosulfate, and the analyses were as follows : $\mathrm{N}$-acetylneuraminic acid $18.5 \%$, hexose $23.5 \%$ (galactose $18.0 \%$, mannose $3.1 \%$ by gas chromatography), hexosamine $22.3 \%$ (glucosamine $14.5 \%$, galactosamine $4.0 \%$ by GC), fucose $1.1 \%$ (by GC), sulfate $3.2 \%$,peptide $20 \%$ (with amino acid analyzer).

\section{Analytical methods}

Sialic acid was determined by the thiobarbituric acid method of Aminoff (1961) after hydrolysis with $0.1 \mathrm{~N} \mathrm{H}_{2} \mathrm{SO}_{4}$ at $80^{\circ} \mathrm{C}$ for $30 \mathrm{~min}$. N-Acetylneuraminic acid isolated from whale cartilage (Nakagawa et al., 1964) was used as a standard. Hexosamine was determined by a method (Svennerholm, 1956) of the ElsonMorgan reaction. Samples were hydrolyzed with $2 \mathrm{~N} \mathrm{HCl}$ for $16 \mathrm{hr}$ at $100^{\circ} \mathrm{C}$ in evacuated, sealed tubes. Hexose was determined by the anthrone method (Yemm and Willis, 1954), reducing sugar by the method of Park and Johnson (1949), and $\mathrm{N}$-acetylhexosamine by a method (Reissig et al., 1955) of the Morgan-Elson reaction.

\section{Gas-liquid chromatography}

Method A. Neutral and amino sugars of heterosaccharides were simultaneously analyzed by gas chromatography after their conversion into alditols and trifluoroacetylation of the alditols. The procedure elaborated by the authors is outlined below. About $1 \mathrm{mg}$ of a sample was hydrolyzed in $0.5 \mathrm{ml}$ of $2 \mathrm{~N}$ trifluoroacetic acid in an evacuated, sealed tube at $100^{\circ} \mathrm{C}$ for $14 \mathrm{hr}$, and the hydrolyzate was evaporated to dryness in a vacuum rotator. The residue was dissolved in $1 \mathrm{ml}$ of water containing $100 \mu \mathrm{g}$ of D-xylose and $250 \mu \mathrm{g}$ of D-mannosamine as internal standards, and about $7 \mathrm{mg}$ of sodium borohydride was added to reduce the sugars. After being left at $5^{\circ} \mathrm{C}$ for $2 \mathrm{hr}$, the $\mathrm{pH}$ of the mixture was lowered to 4-5 with a mixture of conc. HCl-methanol (1: 11, v/v) to destroy the excess borohydride. The solution was evaporated to dryness, followed by repeated evaporation with methanol. The residue was dissolved in $1 \mathrm{ml}$ of $0.005 \mathrm{M}$ potassium borate, and the solution was passed through a column $(0.5 \mathrm{ml})$ of Dowex 1-X8 (200-400 mesh, borate). After the column was washed with $2 \mathrm{ml}$ of water, alditols adsorbed on the column were eluted with $2.5 \mathrm{ml}$ of the above mixture of conc. HCl-methanol, and the eluate was evaporated to dryness. The boric acid was removed as methyl borate by repeated evaporation with methanol. To the residue, $50 \mu 1$ of freshly redistilled tetrahydrofuran and $30 \mu 1$ of trifluoroacetic anhydride were added at $0^{\circ} \mathrm{C}$. The mixture was gently shaken for 30 sec, and allowed to stand at $0^{\circ} \mathrm{C}$ for $15 \mathrm{~min}$. A $1-\mu 1$ aliquot of the reaction mixture was injected to a Shimazu Model GC-1C gas chromatograph equipped with a hydrogen flame ionization detector. Glass columns $(0.4 \times 200 \mathrm{~cm})$ packed with $2 \%$ XF-1105 on acid-washed, silanized Celite 545 (So-100 mesh; Kishida Kagaku Co., Ltd., Osaka) were used.

Method B. About $0.5 \mathrm{mg}$ of an oligosaccharide was hydrolyzed in $2 \mathrm{~N}$ trifluoroacetic acid and evaporated to dryness as described above. The residue was transferred with 1-2 $\mathrm{ml}$ of water to a column $(0.3 \mathrm{ml})$ of Dowex $50-\mathrm{X} 8$ (200-400 mesh, $\mathrm{H}^{+}$), and the column was washed with water. To the effluent and wash- 
ings (neutral sugars) was added $50 \mu \mathrm{g}$ of arabitol as an internal standard, and the mixture was evaporated to dryness. To the residue, $100 \mu 1$ of pyridine, 30 $\mu l$ of hexamethyldisilazane and $15 \mu$ of trimethylchlorosilane were added successively. The mixture was gently shaken for $30 \mathrm{sec}$, and allowed to stand at room temperature. After $30 \mathrm{~min}, 1 \mu \mathrm{l}$ of the reaction mixture was injected to the gas chromatograph. Glass columns $(0.4 \times 200 \mathrm{~cm})$ packed with $5 \%$ SE-30 on Shimalite $\mathrm{W}$ (60-80 mesh) were used. Amino sugars adsorbed on the Dowex 50 column were eluted with $1.5 \mathrm{ml}$ of $2 \mathrm{~N} \mathrm{HCl}$, and the eluate was evaporated to dryness in a vacuum rotator. The residue was dissolved in $0.5 \mathrm{ml}$ of water containing $50 \mu \mathrm{g}$ of arabitol as an internal standard, and the mixture was evaporated to dryness. After being kept in a vacuum desiccator over phosphorus pentoxide and $\mathrm{KOH}$ pellets, the residue was trimethylsilylated and gas chromatographed as described above.

\section{Preparative paper electrophoresis}

Toyo No. 514 paper was washed successively with $2 \mathrm{~N}$ acetic acid, deionized water and a mixture of acetone-ethanol $(1: 1, \mathrm{v} / \mathrm{v})$, and then air-dried. A concentrated solution of neutral oligosaccharides was uniformly applied to the 12$\mathrm{cm}$ starting line on the prewashed paper sheet $(12 \times 40 \mathrm{~cm})$ which had been buf. ferized with $0.05 \mathrm{M}$ sodium borate buffer, $\mathrm{pH} 9.50$, and electrophoresis was carried out at $0.5 \mathrm{~mA}$ per $\mathrm{cm}$ for $3 \mathrm{hr}$. After the paper sheet was dried, both ends were cut off as guide, and stained with alkaline silver nitrate (Trevelyan et al., 1950). The zones corresponding to the spots on the guide strips were cut off, and the oligosaccharide on each zone was eluted with water by the descending technique.

\section{Sodium borohydride reduction}

In order to determine the terminal reducing sugars of oligosaccharides, they were reduced with $\mathrm{NaBH}_{4}$. To l-ml solution of an oligosaccharide (1-3 $\mu$ moles) was added $10 \mathrm{mg}$ of $\mathrm{NaBH}_{4}$. After standing at $5^{\circ} \mathrm{C}$ for $3 \mathrm{hr}$, the $\mathrm{pH}$ of the mixture was lowered to 5 with acetic acid, and passed through a column $(0.5 \mathrm{ml})$ of Dowex 50-X8 (ZOO-400 mesh, $\mathrm{H}^{+}$) to remove the $\mathrm{Na}^{+}$. The effluent and washings were evaporated to dryness in a vacuum rotator, and the boric acid was removed by repeated evaporation with methanol. The reduced oligosaccharide was dissolved in an appropriate volume of water, and analyzed for sialic acid, hexose and hexosamine. The detection and determination of alditol were performed by gas chromatography (Method B).

\section{Preparation of glycosidases}

Neuraminidase was purified essentially according to the procedure of Cassidy et al. (1965) from the culture filtrate of Clostridium perfringens by the combination of ammonium sulfate fractionation, Sephadex G-100 chromatography and DEAEcellulose chromatography. The purified enzyme was free from $\mathrm{N}$-acetylneuraminate aldolase, $\beta$-galactosidase and $\beta$-N-acetylglucosaminidase, and its specific activity (Cassidy et al., 1965) was $\mathbf{8 0}$ units per min per $\mathrm{mg}$ of protein when assayed by using WKS as a substrate.

$\beta$-N-Acetylglucosaminidase and $\beta$-galactosidase were prepared from the liver 
of a marine gastropod, Turbo cornutus. The crude glycosidase solution from the liver of T. cornutus was prepared as described by Muramatsu and Egami (1967). From the glycosidase solution, $\beta$-N-acetylglucosaminidase was purified by $\mathrm{CM}$ cellulose chromatography ( $\mathrm{pH} 4.0$ ) and Sephadex G-ZOO chromatography. The purified preparation was practically free from $\beta$-galactosidase, and its specific activity (Muramatsu, 1968) was 8.5 units.

$\beta$-Galactosidase was purified from the crude glycosidase solution by the combination of column chromatography on CM-cellulose, Sephadex G-200 and hydroxylapatite. The purified enzyme was practically free from $\beta$ - $\mathrm{N}$-acetyglucosaminidase, and its specific activity (Muramatsu, 1967) was 1.3 units.

\section{Periodate oxidation}

Five $\mu$ moles of an oligosaccharide was oxidized in $2 \mathrm{ml}$ of $0.01 \mathrm{M} \mathrm{NaIO}_{4}$ containing $0.05 \mathrm{M}$ sodium acetate buffer, $\mathrm{pH} 4.0$, at $1-2^{\circ} \mathrm{C}$ in the dark. The amount of the oligosaccharide was adjusted so that the quantity of $\mathrm{NaIO}_{4}$ might be in twofold excess over the expected consumption. At appropriate intervals, a $30-\mu 1$ aliquot was withdrawn, and diluted with $5 \mathrm{ml}$ of water. The absorbance of the diluted solution was measured at $223 \mathrm{~m} \mu$ for periodate consumption. Correction was made for iodate formed (Guthrie, 1962). Formaldehyde formation was determined with chromotropic acid as follows. A $0.3-\mathrm{ml}$ aliquot of the oxidation mixture was transferred to a glass-stoppered tube to which was added 0.5 $\mathrm{ml}$ of $0.2 \mathrm{M} \mathrm{NaAsO}_{2}$. The mixture was allowed to stand for $30 \mathrm{~min}$ in the dark at room temperature, and then $4 \mathrm{ml}$ of chromotropic acid reagent (MacFadyen, 1945) was added. After heating at $100^{\circ} \mathrm{C}$ for $30 \mathrm{~min}$, the reaction mixture was cooled in running water, and the purple color was measured at $570 \mathrm{~m} \mu$. A standard formaldehyde solution was prepared by periodate oxidation of D-glucitol.

\section{Periodate oxidation and subsequent borohydride reduction}

One $\mu$ mole of an oligosaccharide was oxidized in $1 \mathrm{ml}$ of $0.02 \mathrm{M} \mathrm{NaIO}_{4}$ containing $0.05 \mathrm{M}$ sodium acetate buffer, $\mathrm{pH} 4.0$, at $1-2^{\circ} \mathrm{C}$ for $48 \mathrm{hr}$ in the dark. To remove the excess periodate, about lmg of $\mathrm{BaCO}_{3}$ was added to the oxidation mixture. After shaking for 15 min the suspension ( $\mathrm{pH} 7$ ) was centrifuged, and the precipitate was washed with water. To the supernatant and washings $(2 \mathrm{ml})$ was added $7 \mathrm{mg}$ of $\mathrm{NaBH}_{4}$ and the mixture was allowed to stand at $5^{\circ} \mathrm{C}$ for 12 hr. After being brought to pH 5 with acetic acid, the mixture was passed through a column (1 ml) of Dowex 50-X8 (200-400 mesh, $\left.\mathrm{H}^{+}\right)$, and the effluent and washings were evaporated to dryness under reduced pressure. The boric acid was removed by repeated evaporation with methanol. The residue was dissolved in an appropriate volume of water, and analyzed for hexose and hexosamine by the cysteine- $\mathrm{H}_{2} \mathrm{SO}_{4}$ method (Dische, 1962) and the Elson-Morgan reaction, respectively.

\section{RESULTS}

\section{Acetolysis of WKS}

Four hundred milligrams of WKS was suspended in a cold mixture of acetic anhydride (12 ml), glacial acetic acid (12ml) and conc. $\mathrm{H}_{2} \mathrm{SO}_{4}(1.2 \mathrm{ml})(\mathrm{Kuhn}$ and 
Wiegandt, 1963). The suspension was stirred at $5^{\circ} \mathrm{C}$ for $24 \mathrm{hr}$, then at $20^{\circ} \mathrm{C}$ for an additional $120 \mathrm{hr}$. A large portion of the starting material still remained insoluble even at. the end of the acetolysis period. The reaction mixture was poured into $500 \mathrm{~g}$ of ice water, and brought to $\mathrm{pH} 4$ with $\mathrm{Na}_{2} \mathrm{CO}_{3}$. Sugar acetates were extracted from the aqueous solution with four 800-ml portions of chloroform, and the combined extracts were washed thrice with water. After being dried over $\mathrm{Na}_{2} \mathrm{SO}_{4}$, the chloroform solution was evaporated to syrup, followed by repeated evaporation with methanol to remove a trace of acetic anhydride. For deacetylation, the residue was dissolved in $5 \mathrm{ml}$ of methanol, $1.5 \mathrm{ml}$ of a sodium methoxide solution, which was freshly prepared by dissolving $0.25 \mathrm{~g}$ of sodium in $50 \mathrm{ml}$ of methanol (Thompson and Wolfrom, 1963), was added, and the mixture was allowed to stand at room temperature for $45 \mathrm{~min}$. After neutralization with Dowex $50-\mathrm{X} 8\left(\mathrm{H}^{+}\right)$, the solution was evaporated to dryness, and the residue was dissolved in an appropriate volume of water for analysis and fractionation. This material is hereafter referred to as acetolysis products. Approximately $13 \%$ of the sialic acid and $21 \%$ of the hexose present in the starting material were recovered in the acetolysis products, and the rest of them were found in the water layer left after the chloroform extraction. On Sephadex G-15 almost all the acetolysis products were eluted after the void volume of the column, and most of the sialic acid was bound (Fig. 1), suggesting that sialooligosaccharides were present in this products. Gas chromatographic analysis (Method A) of the products revealed that major components except sialic acid were galactose and glucosamine, and a small amount of mannose and only a trace of galactosamine were present (Fig. 2 a).

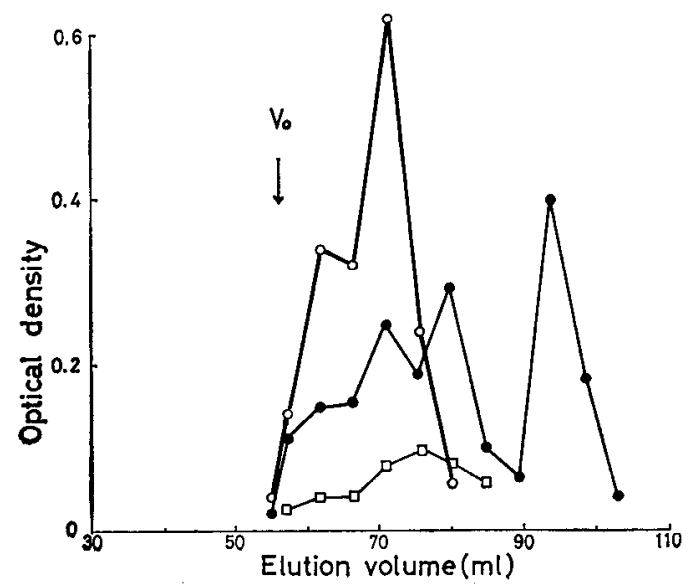

Fig. 1. Gel filtration of acetolysis products on Sephadex G-15. A 0.5-ml solution of the acetolysis products was applied to a column $(1.5 \times 80 \mathrm{~cm})$ of Sephadex G-15 equilibrated with $0.2 \mathrm{M} \mathrm{NaCl}$, and eluted with $0.2 \mathrm{M} \mathrm{NaCl}$. The effluent was analyzed for bound and free sialic acids, and hexose. O-O, 0. D. at $549 \mathrm{~m} \mu$ (bound sialic acid). $\square-\square, 0$. D. at $549 \mathrm{~m} \mu$ (free sialic acid). - -0 . D. at $620 \mathrm{~m} \mu$ (hexose). $\mathrm{V}_{0}$, void volume peak. Bound sialic acid was measured by the thiobarbituric acid method after hydrolysis with $0.1 \mathrm{~N} \mathrm{H}_{2} \mathrm{SO}_{4}$ at $80^{\circ} \mathrm{C}$ for $30 \mathrm{~min}$, and free sialic acid by the same method without hydrolysis. 


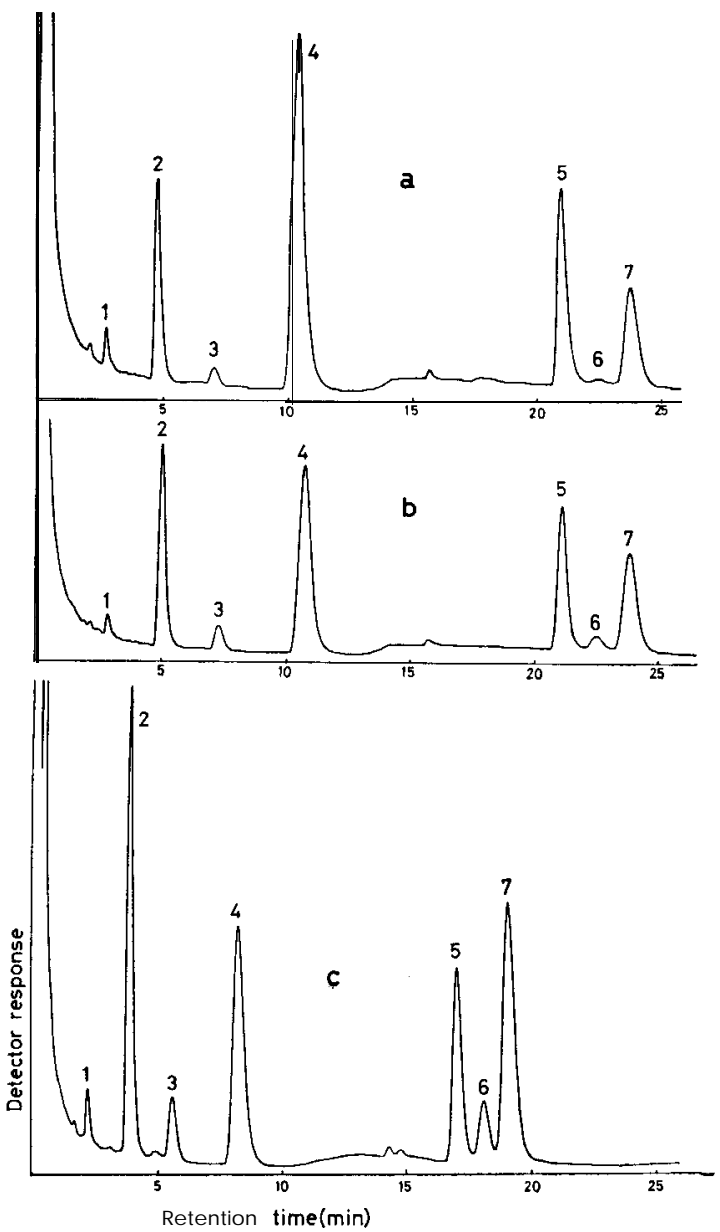

Fig. 2. Gas chromatograms of trifluoroacetyl derivatives of alditols derived from the hydrolyzates of acetolysis products (a), chloroform-nonextractable material (b) and WKS (c). 1, fucose; 2, xylose (internal standard); 3, mannose ; 4, galactose; 5, glucosamine; 6, galactosamine ; 7, mannosamine (i.s.). $\mathrm{N}_{2}$ was used as carrier gas at $50 \mathrm{ml} / \mathrm{min}$. The column temperature was maintained at $135^{\circ} \mathrm{C}$ until the galactose peak emerged, and then raised at $20^{\circ} \mathrm{C} / \mathrm{min}$ to $165^{\circ} \mathrm{C}$.

The chloroform-nonextractable material left in the water layer was recovered as follows. For deacetylation, the water layer was saturated with $\mathrm{Ba}(\mathrm{OH})$, flushed with $\mathrm{N}_{2}$, and stirred gently at $5^{\circ} \mathrm{C}$ for $2 \mathrm{hr}$ in an atmosphere of $\mathrm{N}$. The mixture was neutralized to $\mathrm{pH} 6$ with $\mathrm{H}_{2} \mathrm{SO}$, and centrifuged. The supernatant was concentrated, and chromatographed on Sephadex G-25 (Fig. 3). Most of the material was eluted in the void volume of the column, indicating that it had molecular size similar to that of native WKS. The fraction indicated by the bar was desalted on Sephadex G-15, and then analyzed by gas chromatography (Fig. 2 b). 


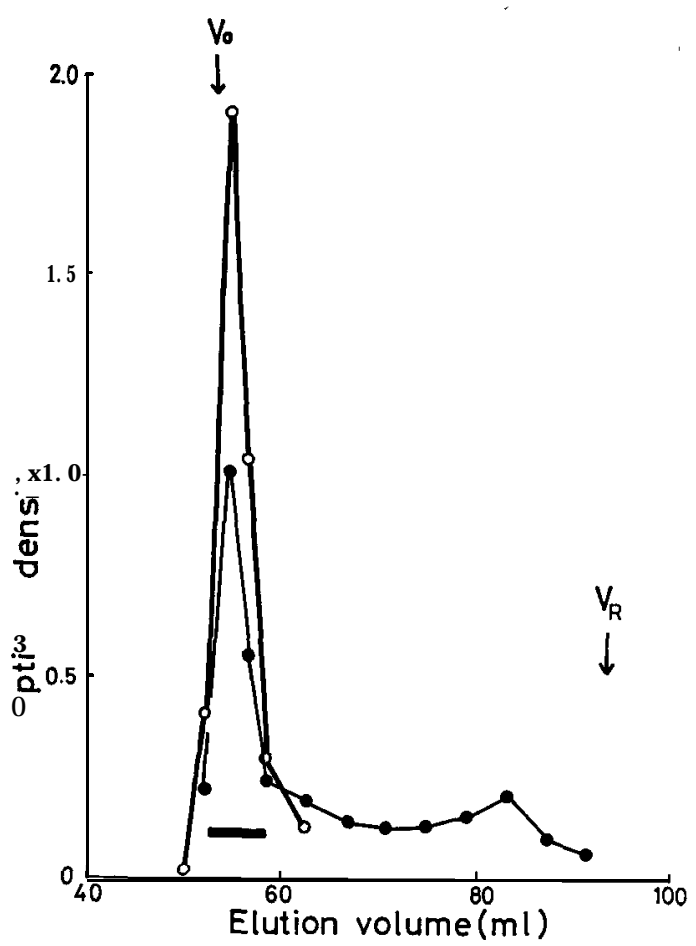

Fig. 3. Gel filtration of chloroform-nonextractable material on Sephadex G-25. A 0.5$\mathrm{ml}$ solution of the chloroform-nonextractable material was applied to a column (1.2X $115 \mathrm{~cm}$ ) of Sephadex G-25 equilibrated with $0.2 \mathrm{M} \mathrm{MaCl}$, and eluted with $0.2 \mathrm{M} \mathrm{NaCl}$. The effluent was analyzed for sialic acid and hexose. O-O, 0. D. at $549 \mathrm{~m} \mu$ (sialic acid). - 0 . D. at $620 \mathrm{~m} \mu$ (hexose). $\mathrm{V}_{\mathrm{0}}$, void volume peak measured with Blue Dextran 2000. $\mathrm{V}_{\mathrm{R}}$, elution volume for raffinose.

\section{Fractionation and purifiication of acetolysis products}

Fractionation and purification of acetolysis products were carried out as summarized in Fig. 4. The acetolysis products were separated on a Dowex 1-X4 column into neutral oligosaccharides and sialooligosaccharides (Fig. 5). The latter oligosacchride fraction indicated by the bar was fractionated on Sephadex G-25 into Fractions S1, S2 and S3 (Fig. 6). Fractions S1 and S2 were further purified on Sephadex G-15 (Fig. 7). The fractions indicated by the bars were desalted on Sephadex G-10, and lyophilized. Oligosaccharides S1 and S2 obtained gave homogeneous spots on paper electrophoresis in $\mathbf{0 . 1} \mathbf{M}$ pyridine-acetate buffer, $\mathrm{pH} 4.5$, by staining with an alkaline silver nitrate dip (Trevelyan et al., 1950).

The neutral oligosaccharide fraction indicated by the bar in Fig. 5 gave six spots on paper chromatography in the solvent system of 1-butanol-pyridine-water $(6: 4: 3, \mathrm{v} / \mathrm{v})$. The oligosaccharides were fractionated on Sephadex G-15 into Fractions N1, N2 and N3 (Fig. 8). On paper chromatography in the above solvent system, Fraction N1 gave two spots with mobilities of galactose and N acetylglucosamine or fucose. Gas chromatography of trifluoroacetyl derivatives 
W KS

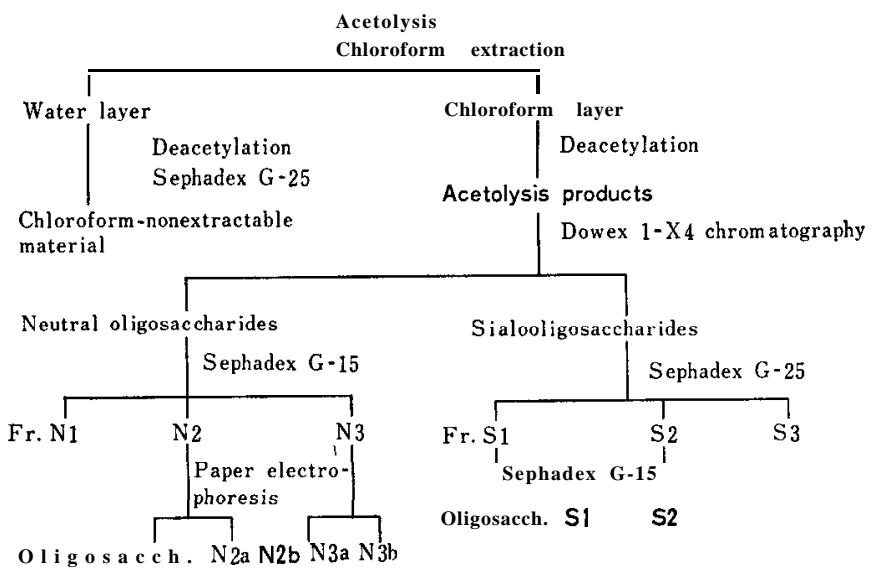

Fig. 4. Scheme of fractionation and purification of acetoiysis products of WKS. The present paper deals with structural studies of Oligosaccharides S1, S2 and N2b.

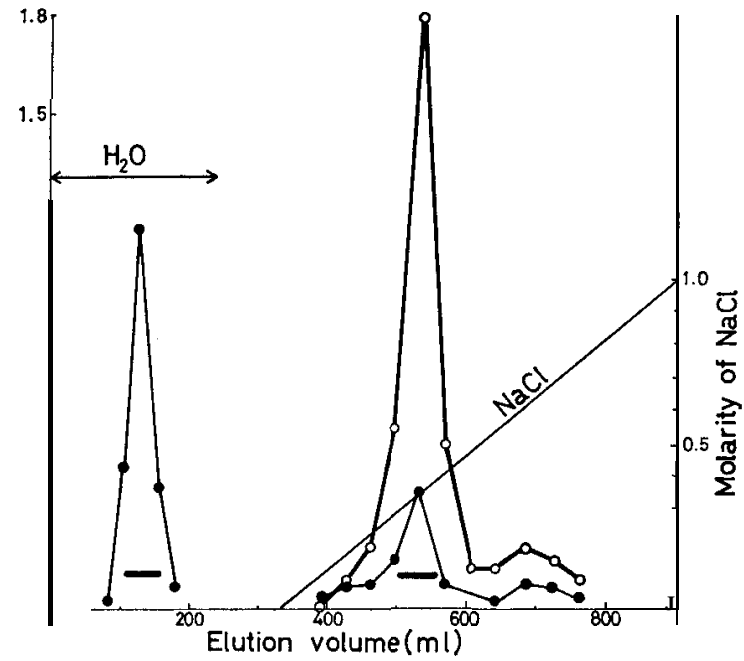

Fig. 5. Fractionation of acetolysis products by Dowex 1-X4 chromatography. Part of the acetolysis products was applied to a column $(2 \times 70 \mathrm{~cm})$ of Dowex 1-X4 $(200-400$ mesh, C1-), and eluted with a column volume of water, followed by elution with a linear gradient of $\mathrm{NaCl}$. The effluent was analyzed for sialic acid and hexose. O-O, 0. D. at $549 \mathrm{~m} \mu$ (sialic acid). O-O, 0. D. at $620 \mathrm{~m} \mu$ (hexose).

of alditols derived from the acid hydrolyzate of Fraction N1 gave three peaks corresponding to fucose, galactose and glucosamine (Fig. 9). Thus, it was proved that this fraction was a mixture of galactose, $\mathrm{N}$-acetylglucosamine and 


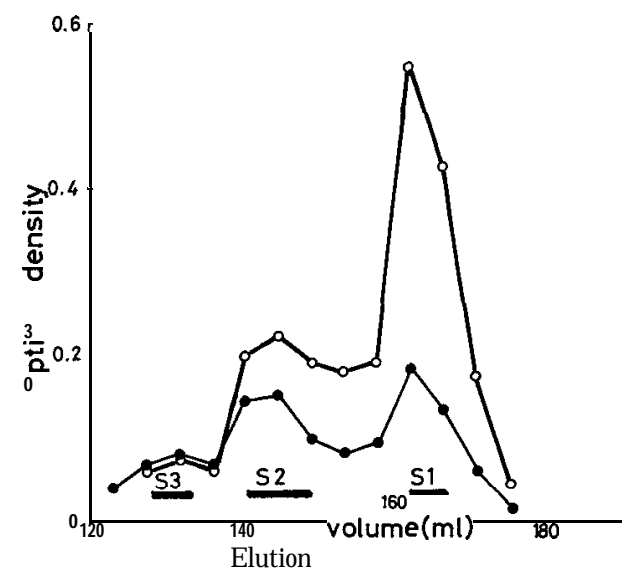

Fig. 6. Fractionation of sialooligosaccharides on Sephadex G-25. The sialooligosaccharide fraction indicated by the bar in Fig. 5 was desalted on Sephadex G-15, and concentrated. A l-ml aliquot of the concentrate was applied to a column $(1.7 \times 106$ $\mathrm{cm}$ ) of Sephadex G-25 equilibrated with $0.2 \mathrm{M} \mathrm{NaCl}$, and eluted with $0.2 \mathrm{M} \mathrm{NaCl}$. The effluent was analyzed for sialic acid and hexose. $0-0,0 . \mathrm{D} . \times 1 / 2$ at $549 \mathrm{~m} \mu$ (sialic acid). - 0 . D. at $620 \mathrm{~m} \mu$ (hexose).

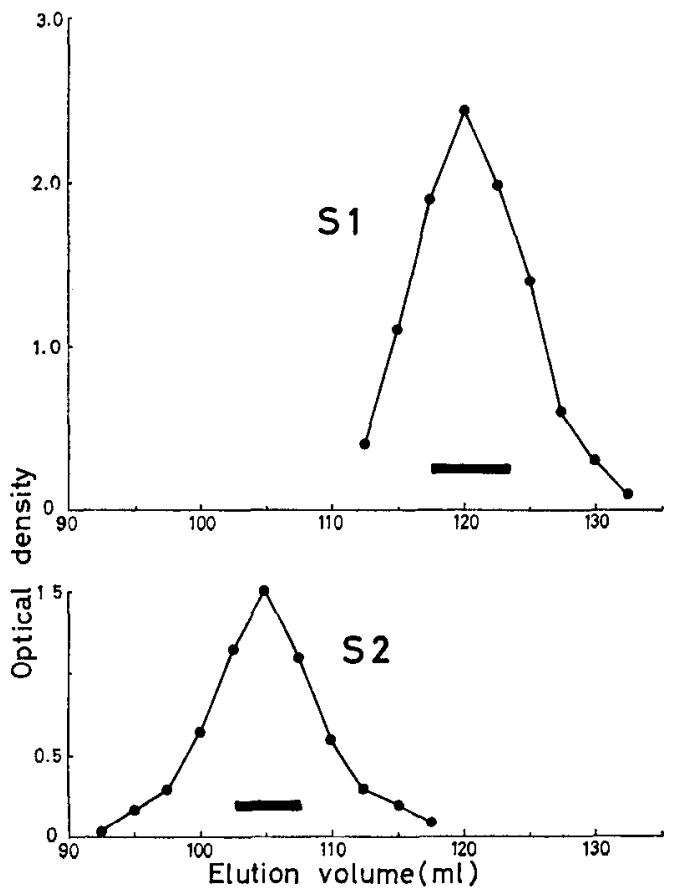

Fig. 7. Gel filtration of Fractions S1 and S2 on Sephadex G-15. Fractions S1 and S2 indicated by the bars in Fig. 6 were desalted on Sephadex G-10, and concentrated. Aliquots $(1 \mathrm{ml})$ of the concentrates were applied separately to the same column (1.7 $\times 117 \mathrm{~cm}$ ) of Sephadex G-15 equilibrated with $0.3 \mathrm{M} \mathrm{NaCl}$. Elution was carried out with $0.3 \mathrm{M} \mathrm{NaCl}$, and the effluent was analyzed by the anthrone reaction. 


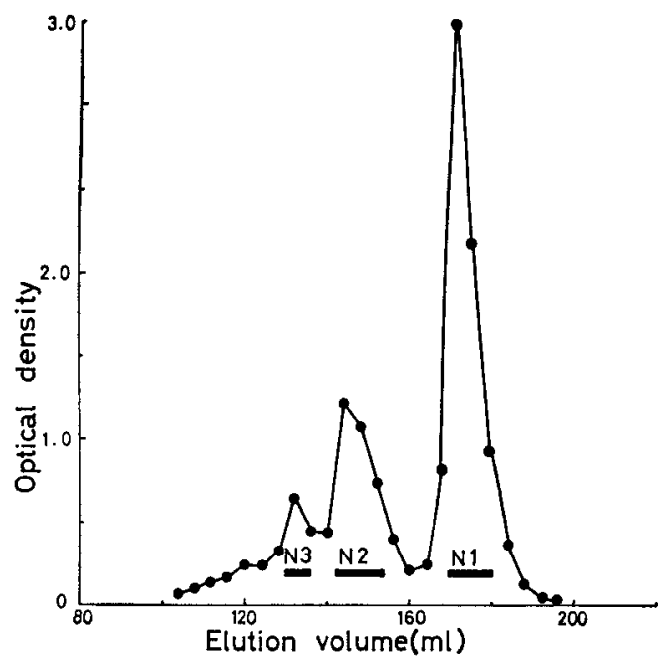

Fig. 8. Fractionation of neutral oligosaccharides on Sephadex G-15. The neutral oligosaccharide fraction indicated by the bar in Fig. 5 was concentrated, a 1-ml aliquot of the concentrate was applied to a column $(1.7 \times 117 \mathrm{~cm})$ of Sephadex G-15 equilibrated with $0.2 \mathrm{M} \mathrm{NaCl}$, and eluted with $0.2 \mathrm{M} \mathrm{NaCl}$. The effluent was analyzed by the anthrone reaction.

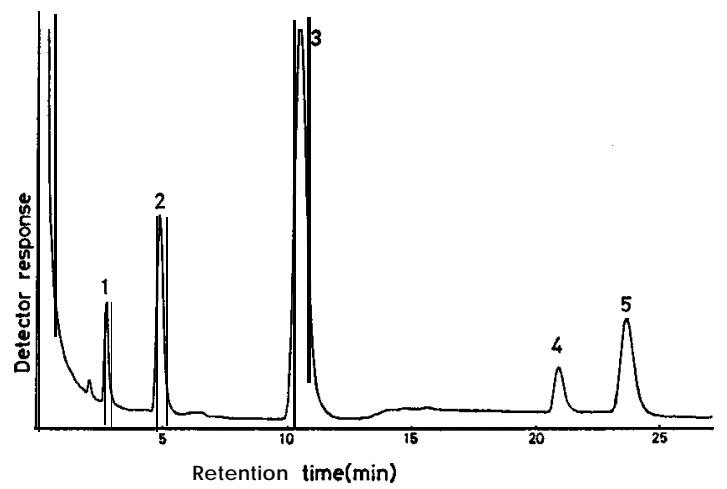

Fig. 9. Gas chromatogram of trifluoroacetyl derivatives of alditols derived from the hydrolyzate of Fraction N1. 1, fucose ; 2, xylose (internal standard) ; 3, galactose ; 4, glucosamine ; 5, mannosamine (i.s.). The conditions used for chromatography were the same as described in Fig. 2.

fucose. Both Fraction N2 and Fraction N3 gave two spots on paper chromatograms. These fractions were desalted by passage through successive columns of Dowex 50-X8( $\left(\mathrm{H}^{+}\right)$and Amberlite IR-45 $\left(\mathrm{OH}^{-}\right)$, concentrated, and fractionated by preparative paper electrophoresis into Oligosaccharides N2a, N2b, N3a and N3b (Fig. 10). After elution from paper with deionized water, these oligosaccharides were passed through columns $(1 \mathrm{ml})$ of Dowex $50-\mathrm{X} 8\left(\mathrm{H}^{+}\right)$, and the effluents were evaporated to dryness, followed by repeated evaporation with methanol to remove boric acid. The residues were dissolved in small volumes of water, and lyophilized, 
N3

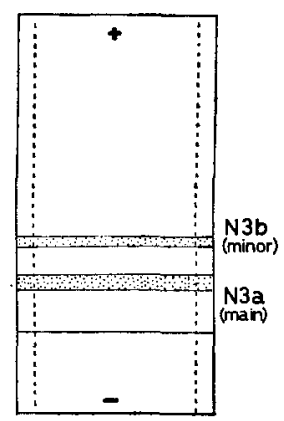

N2

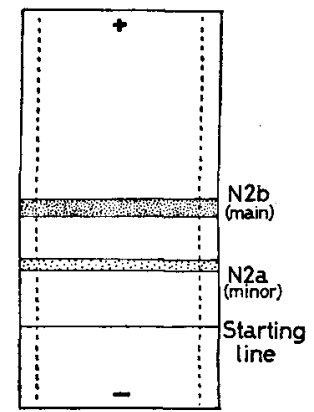

Fig. 10. Electrophoretic fractionation patterns of Fractions N2 and N3. See EXPERIMENTAL for details.

\section{Analyses of oligosaccharides}

The Oligosaccharides S1, S2, N2a, N2b, N3a and N3b were analyzed for sialic acid, hexose, hexosamine and reducing sugar, and the results are shown in Table 1. The sugar components of Oligosaccharides S1, S2, N2b and N3a,

Table 1. Analyses of oligosaccharides obtained by the acetolysis of WKS.

\begin{tabular}{|c|c|c|c|c|c|}
\hline \multirow[b]{2}{*}{ Fraction } & \multicolumn{4}{|c|}{ Molar ratio } & \multirow{2}{*}{$\begin{array}{l}\text { Presumed } \\
\text { composition }\end{array}$} \\
\hline & $\begin{array}{l}\text { N-Acetyl- } \\
\text { neuraminic acid }\end{array}$ & Hexose* & Hexosamine ${ }^{* *}$ & Reducing sugar* & \\
\hline \multirow{3}{*}{$\begin{array}{l}\text { S1 } \\
\text { S2 } \\
\text { N2a } \\
\text { N2b } \\
\text { N3b }\end{array}$} & $\begin{array}{l}0.049 \\
0.0\end{array}$ & \multirow{3}{*}{$\begin{array}{l}1.001 .00 \\
1.00 \\
1.00 \\
1.00\end{array}$} & \multirow{3}{*}{$\begin{array}{l}0.0 \\
0.53 \\
0.45 \\
0.94 \\
0.58\end{array}$} & 0.910 .60 & $\begin{array}{l}\text { disaccharide } \\
\text { tetrasaccharide }\end{array}$ \\
\hline & & & & 1.13 & disaccharide \\
\hline & 0.0 & & & 0.65 & trisaccharide \\
\hline
\end{tabular}

* As galactose.

** As glucosamine.

and Fraction S3 were also examined by gas chromatography (Method A), and it was confirmed that the components of the oligosaccharides except Fraction S3 were galactose and glucosamine (Figs. 11 and 12). Fraction S3 contained a small amount of mannose with a mannose to galactose ratio of $0.3: 1.0$ in addition to galactose and glucosamine. This fraction was slightly heterogeneous on paper electrophoresis under the conditons used for S1 and S2. All the oligosaccharides gave negative tests by the Morgan-Elson and ninhydrin (Yemm and Cocking, 1955) reactions, showing that the reducing ends of the oligosaccharides were either galactose or $\mathrm{N}$-acetylglucosamine substituted at position 4 , and that no amino acids were present. The amounts of Fraction S3 and Oligosaccharides N2a, N3a and N3b were small as compared with those of Oligosaccharides S1, $\mathrm{S} 2$ and $\mathrm{N} 2 \mathrm{~b}$, and insufficient for further analysis.

The infrared spectra to S1 and S2 showed on sulfate peaks at $1240 \mathrm{~cm}^{-1}$ $850 \mathrm{~cm}^{-1}$, and $820 \mathrm{~cm}^{-}$. 


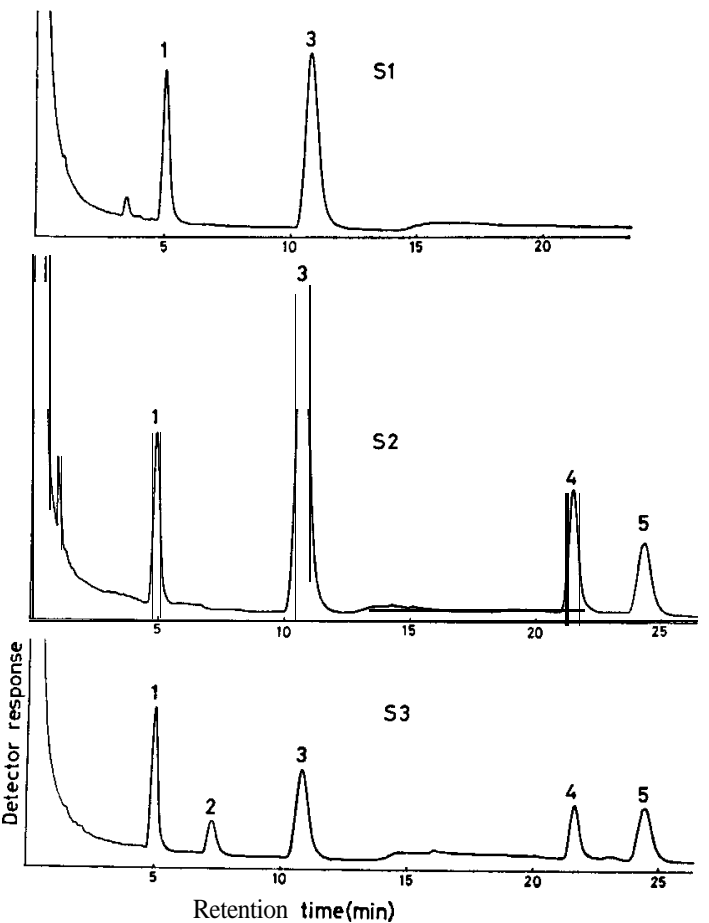

Fig. 11. Gas chromatograms of trifluoroacetyl derivatives of alditols derived from the hydrolyzates of Oligosaccharides S1 and S2, and Fraction S3. 1, xylose (internal standard); 2, mannose; 3, galactose; 4, glucosamine; 5, mannosamine (i.s.). The conditions were the same as described in Fig. 2.
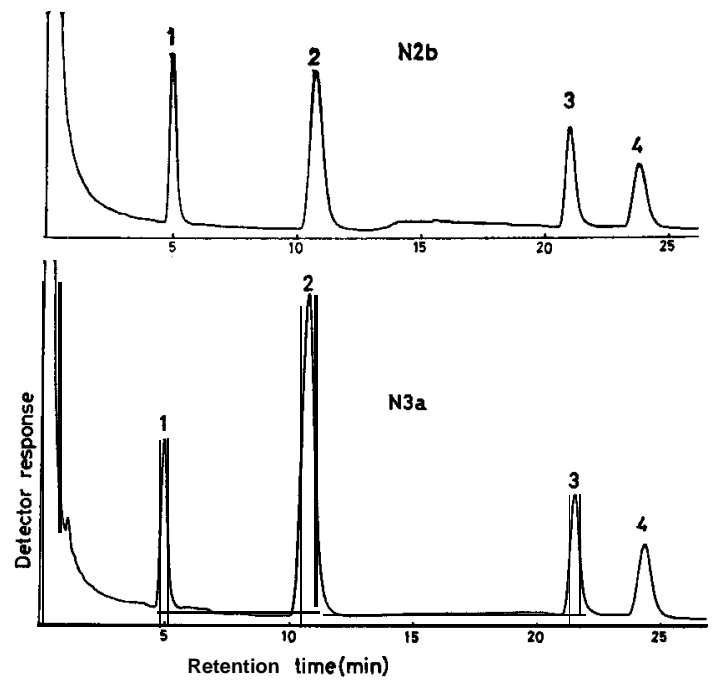

Fig. 12. Gas chromatograms of trifluoroacetyl derivatives of alditols derived from the hydrolyzates of Oligosaccharides N2b and N3a. 1, xylose (internal standard); 2, galactose ; 3, glucosamine ; 4, mannosamine (i.s.). The conditions were the same as described in Fig. 2. 


\section{Estimation of molecular weights of Oligosaccharides $S$ 1, S 2 and N 2b by gel fil- tration}

Molecular weights of S1, S2 and N2b were roughly estimated to be approximately 500, 1000 and 400, respectively, by gel filtration on Sephadex G-15 (Fig. 13). These values are in agreement with the compositions of the oligosaccharides presumed from the reducing sugar values (Table 1). From the molecular weights and the molar ratios of components, S1, S2 and N2b were proved to be a disaccharide composed of $\mathrm{N}$-acetylneuraminic acid and galactose, a tetrasaccharide composed of $\mathrm{N}$-acetylneuraminic acid, galactose and $\mathrm{N}$-acetylglucosamine in a molar ratio of $1: 2: 1$, and a disaccharide composed of galactose and $\mathrm{N}$ acetylglucosamine, respectively.

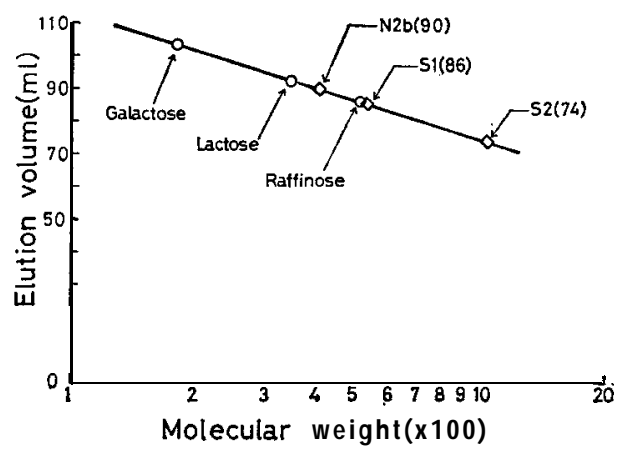

Fig. 13. Estimation of molecular weights of Oligosaccharides $\mathrm{S} 1, \mathrm{~S} 2$ and N2b by gel filtration on Sephadex G-15. A 0.5-ml solution containing $1.5 \mathrm{mg}$ of an oligosaccharide was applied to a column $(1.4 \times 103 \mathrm{~cm})$ of sephadex G-15 equilibrated with $0.3 \mathrm{M}$ $\mathrm{NaCl}$, and eluted with $0.3 \mathrm{M} \mathrm{NaCl}$ at $4 \mathrm{ml} / \mathrm{hr}$. Fractions of $2.1 \mathrm{ml}$ were collected, and analyzed by the anthrone reaction. The elution volumes thus obtained for S1, S2 and $\mathrm{N} 2 \mathrm{~b}$ are given in parentheses. The standard curve was made by plotting the elution volumes of galactose, lactose and raffinose, which were subjected in admixture to gel filtration under the same conditions, against the logarithms of their molecular weights. The void volume of the column was $57 \mathrm{ml}$.

\section{Analyses of Oligosaccharides S 1, S 2 and N 2b after borohydride reduction}

By treatment of oligosaccharides with $\mathrm{NaBH}_{4}$, their terminal reducing sugars are converted almost quantitatively into the corresponding alditols which are negative to the anthrone and Elson-Morgan reactions. On the basis of this

Table 2. Analyses of oligosaccharides before and after borohydride reduction. Values are expressed as micromoles.

\begin{tabular}{l|c|c|c|c}
\hline & $\begin{array}{c}\text { N-Acetyl- } \\
\text { neuraminic acid }\end{array}$ & Galactose & Glucosamine & Galactitol* \\
\hline S1 & 2.40 & 2.46 & 0 & 0 \\
S1 reduced & 2.28 & 0 & 1.64 & 0 \\
S2 & 1.50 & 3.10 & 1.56 & 1.10 \\
S2 reduced & 1.37 & 1.42 & 2.38 & 2.08 \\
N2b reduced & 0 & $\mathbb{2 . 4 5}$ & 25 \\
\hline
\end{tabular}

* Determined by gas chromatography (Method B). 


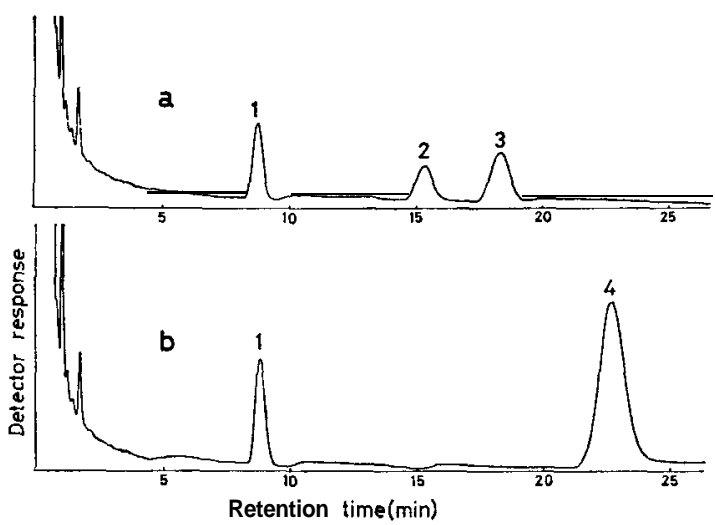

Fig. 14. Gas chromatographic analysis of Disaccharide $\mathrm{S} 1$ before and after borohydride reduction. a: Before reduction. b: After reduction. 1, arabitol (internal standard) : 2, 3, galactose ; 4, galactitol. Carrier gas: $\mathrm{N}_{2}$. Column temperature : $180^{\circ} \mathrm{C}$.
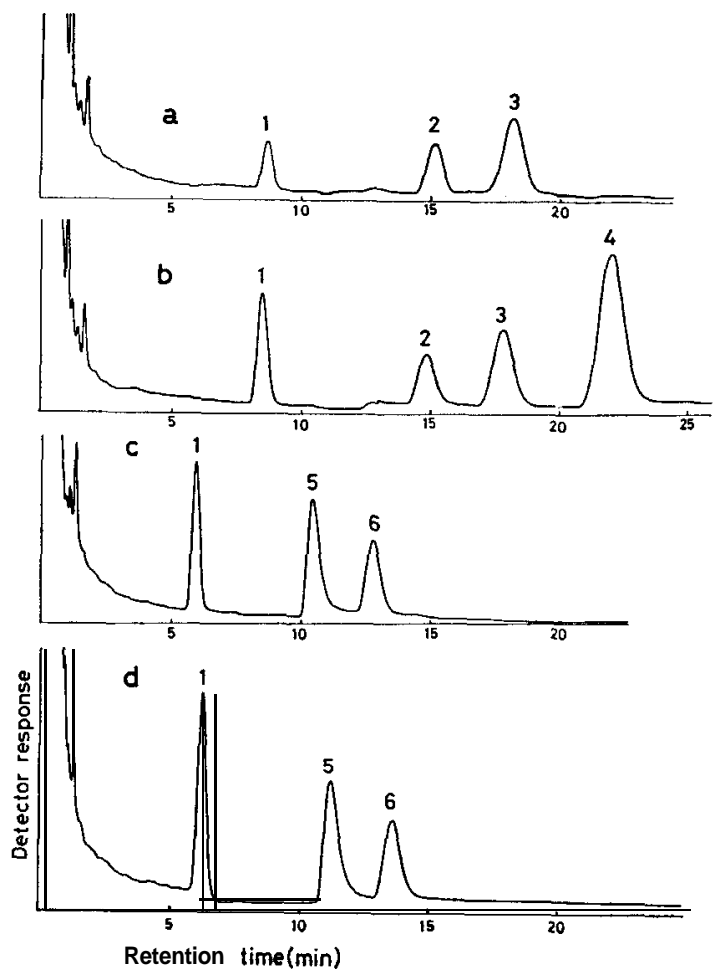

Fig. 15. Gas chromatographic analysis of Tetrasaccharide $\mathrm{S} 2$ before and after borohydride reduction. a: Before reduction, neutral sugar. b: After reduction, neutral sugar. c: Before reduction, amino sugar. d:After reducton, amino sugar. 1, arabitol (i. s.) ; 2, 3, galactose ; 4,galactitol; 5, 6, glucosamine. Column temperature : neutral sugar, $180^{\circ} \mathrm{C}$; amino sugar, $190^{\circ} \mathrm{C}$. 


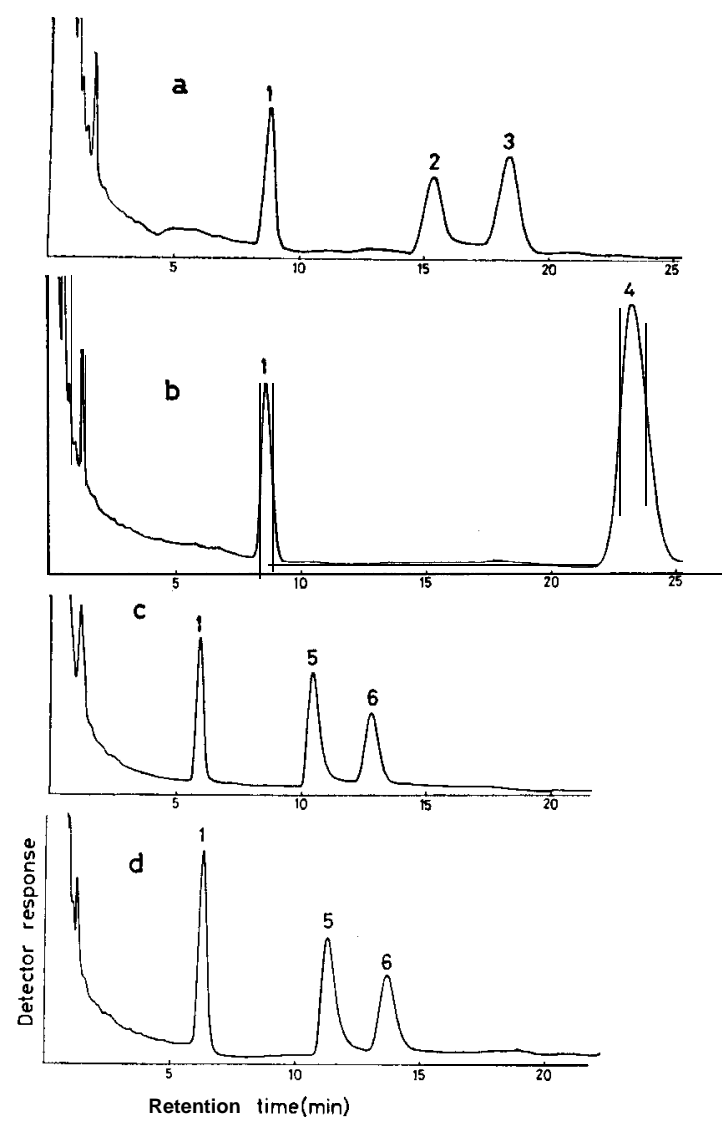

Fig. 16. Gas chromatographic analysis of Disaccharide N2b before and after borohydride reduction. a: Before reduction, neutral sugar. b: After reduction, neutral sugar. c : Before reduction, amino sugar. d: After reduction, amino sugar. 1, arabitol (i. s.) ; 2, 3, galactose ; 4 , galactitol ; 5,6 , glucosamine. Column temperature : neutral sugar, $180^{\circ} \mathrm{C}$; amino sugar, $190^{\circ} \mathrm{C}$.

principle, the terminal reducing sugars of $\mathrm{S} 1, \mathrm{~S} 2$ and $\mathrm{N} 2 \mathrm{~b}$ were estimated by the changes in analysis resulting from their borohydride reduction. The terminal sugars were also confirmed by the gas chromatographic analysis (Method B) of alditols formed. The colorimetric and gas chromatographic analyses of S1, $\mathrm{S} 2$ and N2b before and after borohydride reduction are shown in Table 2, and Figs. 14, 15 and 16. After treatment of the oligosaccharides with $\mathrm{NaBH}_{4}$, the galactose values dropped to zero or one half while the glucosamine values remained unchanged, indicating that the reducing ends of them were galactose. This was also confirmed by the fact that galactitol was detected as the only reduced sugar by gas chromatography after hydrolysis of the reduced oligosaccharides. Thus, the galactose residues of $\mathrm{S} 1$ and $\mathrm{N} 2 \mathrm{~b}$ were completely converted into galactitol. It is evident from this result that they were $\mathrm{N}$-acetylneuraminylgalactose, and $\mathrm{N}$-acetylglucosaminyl-galactose, respectively. The galactose value of S2 dropped to one half of its original value, indicating that S2 was a tetra- 
saccharide with the galactose at the reducing end.

\section{Enzymatic hydrolyses of Oligosaccharides S 1, S 2 and N 2b with glycosidases}

The sequential arrangement of the sugar residues in S1, S2 and N2b was studied enzymatically. They were incubated with glycosidases under the conditions specified, and aliquots of the incubation mixtures were directly analyzed for the released $\mathrm{N}$-acetylneuraminic acid and $\mathrm{N}$-acetylglucosamine. The released galactose was estimated by gas chromatography as follows. The remainders of the incubation mixtures were passed through successive columns $(1 \mathrm{ml})$ of Dowex 1-X8 (acetate) and Dowex 50-X2 $\left(\mathrm{H}^{+}\right)$, and the effluents and washings to which $60 \mu \mathrm{g}$ of mannitol was added as an internal standard were evaporated to dryness in a vacuum rotator. The residues were trimethylsilylated, and analyzed by gas chromatography (Method B). Table 3 summarizes the enzymatic hydrolyses of S1, S2 and N2b with neuraminidase, $\beta$-galactosidase and $\beta-\mathrm{N}$ acetylglucosaminidase. Incubation of $\mathrm{S} 1$ with neuraminidase resulted in release of equimolar amounts of $\mathrm{N}$-acetylneuraminic acid and galactose. By treatment of S2 with neuraminidase, almost all the $\mathrm{N}$-acetylneuraminic acid was released without liberation of the other components. When S2 was incubated with $\beta-$ galactosidase and $\beta$-N-acetylglucosaminidase without pretreatment by neuraminidase, none of the galactose and $\mathrm{N}$-acetylglucosamine were released. However, incubation of $\mathrm{S} 2$ with $\beta$-galactosidase following neuraminidase treatment resulted in release of 0.7 mole of galactose per mole of $\mathrm{S} 2$. This indicates that

Table 3. Release of monosaccharides from Oligosaccharides Sl, S2 and N2b by glycosidases. All values are expressed as moles of monosaccharides released per mole of oligosaccharides.*

\begin{tabular}{c|c|c|c|c}
\hline \multirow{2}{*}{ Oligosaccharide } & \multicolumn{3}{|c}{ Monosaccharide released } \\
\hline S1 & $\begin{array}{l}\text { G-Acetyl- } \\
\text { neuraminic acid }\end{array}$ & Galactose & $\begin{array}{c}\text { N-Acetyl- } \\
\text { glucosamine }\end{array}$ \\
\hline S2 & $\begin{array}{l}\text { G-Galactosidase (1) and } \\
\beta-N \text {-acetylglucosaminidase (2) } \\
\text { Neuraminidase, then } \\
\beta \text {-galactosidase ( 3) } \\
\beta \text { N2b }\end{array}$ & 0.95 & 0.920 & 0 \\
\hline
\end{tabular}

* The molecular weights of S1, S2 and N2b were calculated to be 471,836 and 383 respectively, based on their molar ratios of components and compositions.

(1) To a solution of $0.75 \mu$ mole of $\mathrm{S} 1$ in $0.5 \mathrm{ml}$ of $0.03 \mathrm{M}$ citrate buffer, $\mathrm{pH} 5.0$, was added a $0.2-\mathrm{ml}$ solution of neuraminidase (1.6 units), and the mixture was incubated at $37^{\circ} \mathrm{C}$ for $3 \mathrm{hr}$. (2) $\mathrm{To}$ a solution of $0.6 \mu$ mole of $\mathrm{S} 2$ in $0.5 \mathrm{ml}$ of the citrate buffer were added a $0.5-\mathrm{ml}$ solution of $\beta$-galactosidase $(0.7$ unit) and a $0.2-\mathrm{ml}$ solution of $\beta-\mathrm{N}$-acetylglucosaminidase (1.4 units), and the mixture was incubated at $37^{\circ} \mathrm{C}$ for $20 \mathrm{hr}$ with a drop of toluene. (3) To a solution of $0.6 \mu$ mole of S2 in $0.5 \mathrm{ml}$ of the citrate buffer was added the $0.2-\mathrm{ml}$ solution of neuraminidase, and the mixture was incubated at $37^{\circ} \mathrm{C}$ for $3 \mathrm{hr}$. The incubation mixture was immersed in a boiling water bath for $2 \mathrm{~min}$, and evaporated to dryness under reduced pressure. The residue was dissolved in $0.5 \mathrm{ml}$ of the citrate buffer, the $0.5-\mathrm{ml}$ solution of $\beta$-galactosidase was added, and the mixture was incubated at $37^{\circ} \mathrm{C}$ for $20 \mathrm{hr}$ with a drop of toluene. (4) To a solution of $1.0 \mu$ mole of N2b in $0.5 \mathrm{ml}$ of the citrate buffer was added the $0.2-\mathrm{ml}$ solution of $\beta-\mathrm{N}$-acetylglucosaminidase, and the mixture was incubated at $37^{\circ} \mathrm{C}$ for $5 \mathrm{hr}$. 
the galactose was located next to $\mathrm{N}$-acetylneuraminic acid, and its anomeric linkage was $\beta$-configuration. Upon treatment with $\beta$ - $\mathrm{N}$-acetylglucosaminidase, $\mathrm{N} 2 \mathrm{~b}$ was almost completely cleaved into equimolar amounts of $\mathrm{N}$-acetylglucosamine and galactose, suggesting the presence of a $\beta$-N-acetylglucosaminidic linkage.

\section{Periodate oxidation of Disaccharides $S 1$ and $\mathbf{N} 2 b$}

Periodate oxidations of $\mathrm{S} 1$ and $\mathrm{N} 2 \mathrm{~b}$ were carried out to elucidate the linkages between their sugar components. S1 consumed rapidly 2 mole of periodate with formation of 1 mole of formaldehyde, and then consumed slowly an additional mole of periodate without formaldehyde formation (Fig. 17). The rapid periodate consumption accompanied by formaldehyde formation was presumably due to the N-acetylneuraminic acid residue (Neuberger et al., 1966). Accordingly, it is realized that an additional mole of periodate was consumed slowly by the galactose residue, indicating that the linkage of $\mathrm{N}$-acetylneuraminic acid to galactose was $2 \rightarrow 3$ or $2 \rightarrow 2$. N2b consumed 2 moles of periodate, and no formaldehyde formation was observed (Fig. 17). It is obvious that the galactose residue consumed 1 mole of periodate since the $\mathrm{N}$-acetylglucosamine located at nonreducing end consumes 1 mole of periodate. This result indicates that the linkage of $\mathrm{N}$-acetylglucosamine to galactose was $1 \rightarrow 3$ or $1 \rightarrow 2$.

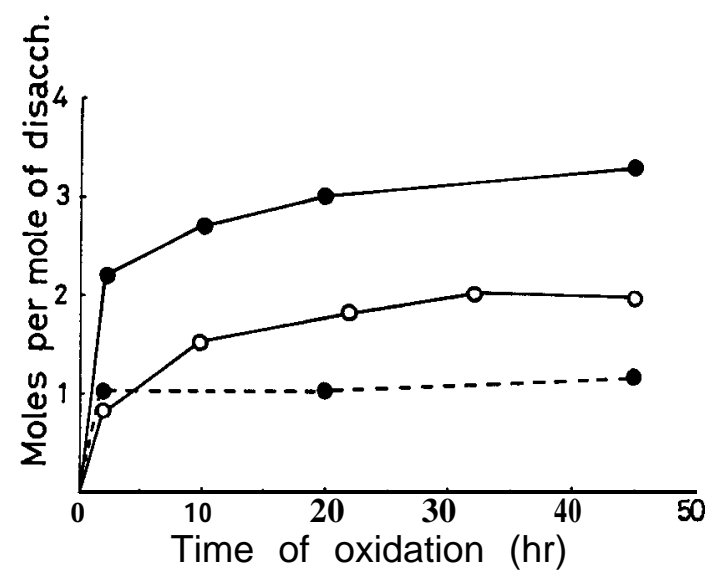

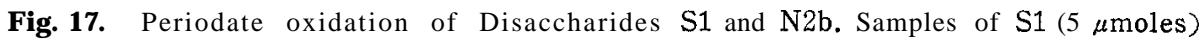
or N2b ( $5 \mu$ moles) were oxidized under the conditions described in EXPERIMENTAL. At the indicated times, aliquots were removed for the determination of formaldehyde and residual periodate. $\bullet-\mathrm{S} 1, \mathrm{I}_{4}^{-}$consumed ; O---O : $\mathrm{S} 1$, HCHO formed; O-O: $\mathrm{N} 2 \mathrm{~b}$, $\mathrm{IO}_{4}^{-}$consumed. No formaldehyde was formed from N2b.

\section{reduction \\ Analysis of Tetrasaccharide $\mathbf{S} 2$ after periodate oxidation and subsequent borohydride}

The sugar sequence of $\mathrm{S} 2$ was proved to be $\mathrm{N}$-acetylneuraminyl-galactosyl$\mathrm{N}$-acetylglucosaminyl-galactose from the results obtained by the reducing end and sequence analyses described above. In order to clarify the linkages among these sugars, S2 subjected to periodate oxidation followed by borohydride reduction was analyzed for residual sugars (Table 4). After the oxidation, all the sialic acid and half the galactose, which were at nonreducing and reducing ends 
Table 4. Analysis of Tetrasaccharide S2 before and after treatments with periodate and borohydride.

\begin{tabular}{l|c|c|c}
\hline & N-Acetylneuraminic acid & Galactose & Glucosamine \\
\hline Before & $0.98 \mu$ mole & 2.00 & 1.06 \\
After & $0^{*}$ & 0.90 & 0.82 \\
\hline
\end{tabular}

* Examined qualitatively by the direct Ehrlich reaction (Werner and Odin, 1952).

respectively, were destroyed, showing that the galactosyl-N-acetylglucosaminylmoiety between both the ends was not attacked by periodate. This results indicate the following linkages : $\mathrm{N}$-acetylneuraminic acid- $(2 \rightarrow 3)$-galactose- $(1 \rightarrow 4$ or 3)-N-acetylglucosamine-.

\section{DISCUSSION}

The acetolysis of WKS was performed with continuous stirring since WKS was almost insoluble in the acetic anhydride-acetic acid- $\mathrm{H}_{2} \mathrm{SO}_{4}$ mixture throughout acetolysis. The low yield of the acetolysis products and the presence of almost undegraded WKS were probably due to the poor solubility of WKS in the mixture.

Most of sialic acid in the acetolysis products was bound, suggesting that the ketosidic linkage of sialic acid was fairly stable to acetolysis though it is very labile to acid hydrolysis.

The periodate oxidation study of S1 did not provide conclusive proof that the linkage of $\mathrm{N}$-acetylneuraminic acid to galactose was $2 \rightarrow 3$. However, the $\mathrm{N}$ acetylneuraminic acid to galactose linkage in $\mathrm{S} 2$, which is likely to have formed $\mathrm{S} 1$ by its further degradation, was proved to be $2 \rightarrow 3$ by the analysis of residual sugars following periodate oxidation. Moreover, the authors have demonstrated in the following study (Nakagawa and Satake, in preparation) that all the sialic acid of WKS is linked to position 3 of galactose at the nonreducing end. Desialyzed WKS which was prepared by neuraminidase treatment, and native WKS were submitted to Smith degradation (Goldstein et al., 1965), and the residual sugars and degradation products were analyzed. The Smith degradation of desialyzed WKS resulted in a loss of galactose practically equal to the amount of $\mathrm{N}$-acetylneuraminic acid removed, accompanied by production of glycerol and glycolaldehyde equal to the amount of the degraded galactose, while the galactose

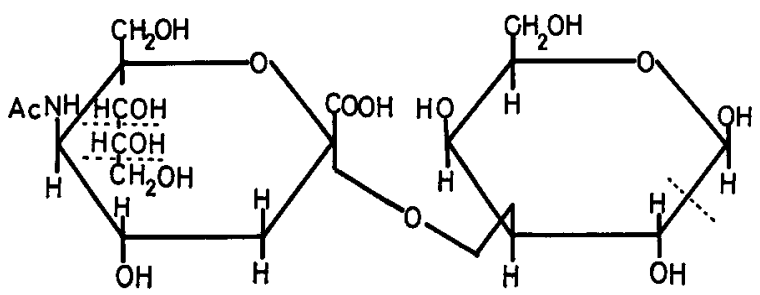

Fig. 18. Structure of Disaccharide $\mathrm{S} 1: \mathrm{N}$-acetylneuraminyl-(2 $\rightarrow 3)-\beta$-D-galactopyranose. Dotted lines show sites of periodate oxidation. 
residue of the native WKS was practically undegraded. It is evident from these results that $\mathrm{S} 1$ was $\mathrm{N}$-acetylneuraminyl-(2 $\rightarrow 3)$-D-galactose (Fig. 18). The anomeric linkage is probably a-configuration since S1 was susceptible to neuraminidase which is considered to be an a-glycosidase (Rafelson et al., 1966).

The N-acetylglucosaminidic linkage in Disaccharide N2b was shown to be either $1 \rightarrow 3$ or $1 \rightarrow 2$ by the periodate oxidation study. Bhavanandan and Meyer (1968) have isolated 2, 4-di-O-methylgalactose and 2, 4, 6-tri-O-methylgalactose as major methylated galactose from the hydrolyzate of methylglycosides obtained by the methanolysis of fully methylated human rib cartilage keratosulfate. Their result indicated that positions 2 and 4 of the galactose residues in the keratosulfate were not substituted by glycosidic bonds. In addition, they have isolated a disaccharide tentatively identified as glucosaminyl-(l-+3)-galactose from the $2 \mathrm{~N} \mathrm{H}_{2} \mathrm{SO}_{4}$ hydrolyzate $\left(100^{\circ} \mathrm{C}, 15 \mathrm{hr}\right)$ of the keratosulfate. Judging from the present result and these data, the $\mathrm{N}$-acetylglucosaminidic linkage in $\mathrm{N} 2 \mathrm{~b}$ is fairly presumed to be $1 \rightarrow 3$, and its anomeric form is @configuration since the linkage was easily cleaved by $\beta-\mathrm{N}$-acetylglucosaminidase (Fig. 19).

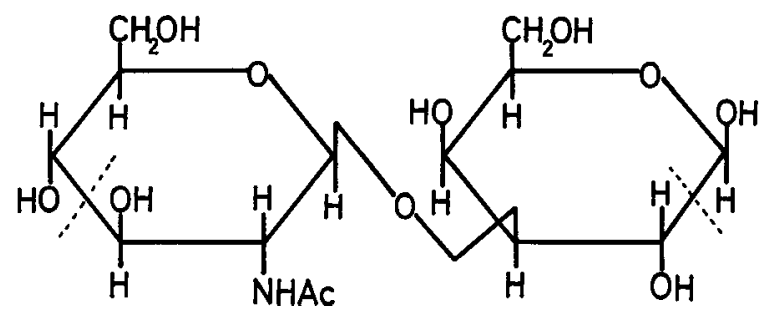

Fig. 19. Probable structure of Disaccharide N2b:2-acetamido-2-deoxy- $\beta$-D-glucopyranosyl-(1 $\rightarrow 3)-\beta$-D-galactopyranose. Dotted lines show sites of periodate oxidation.

The sugar sequence of Tetrasaccharide $\mathrm{S} 2$ was proved to be $\mathrm{N}$-acetylneuraminyl-galactosyl-N-acetylglucosaminyl-galactose from the results obtained by the reducing end analysis and enzymatic hydrolysis. S2 is considered to be made up of Disaccharides S1 and N2b through the galactosidic linkage. The linkage of galactose to $\mathrm{N}$-acetylglucosamine in $\mathrm{S} 2$ was shown to be either $1 \rightarrow 4$ or $1 \rightarrow 3$ by the analysis of residual sugars following periodate oxidation. Bhavanandan and Meyer (1968) have isolated 3-O-methylglucosamine, 3, 6-di-O-methylglucosamine, 3-O-methyl-N-methylglucosamine and 3, 6-di-O-methyl-N-methylglucosamine in the methylation study described above, showing that position 4 of the glucosamine residues in human rib cartilage keratosulfate were not substituted by glycosidic bonds. Furthermore, the linkage of galactose to N-acetylglucosamine is exclusively $\beta-(1 \rightarrow 4)$ in the carbohydrate chains of a number of glycoproteins so far studied, including fetuin, $\alpha_{i}$-acid glycoprotein, a,-macroglobulin, thyroglobulin, etc. (Spiro, 1970). Therefore, the galactosidic linkage in S2 is possibly $\beta-(1 \rightarrow 4)$ (Fig. 20 ).

Since sialic acid is present at the nonreducing end, it is obvious that Sialooligosaccharides S1 and S2 were derived from the external portion (terminal nonreducing region) of WKS. It is presumed that most of the acetolysis products were derived from the external portion, and that the internal portion 


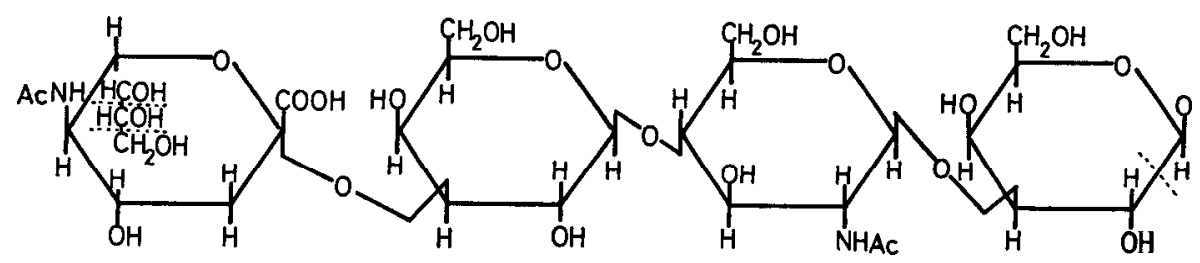

Fig. 20. Probable structure of Tetrasaccharide $\mathrm{S} 2$ : N-acetylneuraminyl-(2-*3)-,\&Dgalactopyranosyl- $(1 \rightarrow 4)$-2-acetamido-2-deoxy- $\beta$-D-glucopyranosyl- $(1 \rightarrow 3)$ - $\beta$-D-galactopyranose. Dotted lines show sites of periodate oxidation.

remained in the water layer, presumably because of the peptide and sulfate groups attached. The sugar components of all the oligosaccharides obtained in purified forms were galactose and glucosamine. However, Fraction S3 (Fig. 6), which was analyzed after desalting on Sephadex G-13, contained mannose in addition to these sugars (Fig. 11). The elution pattern from the Sephadex G-25 column (Fig. 6) showed that this fraction was the largest fragment in the acetolysis products. These data suggest that the mannose residue was present in the internal portion (glycopeptide bond region) of WKS.

Only a trace of galactosamine was detected in the acetolysis products (Fig. 2 a). Hence, the galactosamine of WKS is likely to be also present in the internal portion. It has been demonstrated in cartilage keratosulfate that galactosamine was involved in the linkages between the carbohydrate chain and the threonine and serine residues in the peptide chain (Bray et al., 1967; Seno and Toda, 1970). The authors have also confirmed that a part of galactosamine of WKS was involved in the linkage.

Ester sulfate groups were not detected in all the oligosaccharides obtained in purified forms. However, the small fraction eluted finally from the Dowex 1-X4 column (Fig. 5), which was analyzed after desalting on Sephadex G-15 without further purification, contained sulfate with a sulfate to glucosamine ratio of $0.7: 1.0$. The chemical composition of this fraction was similar to that of Tetrasaccharide S2. Therefore, it may be possible that S2 lost on acetolysis a sulfate group which had been attached to one of the sugar residues.

The occurrence of $\mathrm{N}$-acetylneuraminyl-(2 $\rightarrow 3)$-galactosyl-(1 $\rightarrow 4)-\mathrm{N}$-acetylglucosaminyl-(1-+3)-galactosyl-moiety in keratosulfate was demonstrated for the first time in this study. However, the N-acetylneuraminyl-(2 $\rightarrow 3)$-galactosyl- $(1 \rightarrow$ 4) -N-acetylglucosamine unit has been confirmed in heteropolysaccharide chains of several glycoproteins such as fetuin (Spiro, 1964), $\alpha_{1}$-acid glycoprotein (Wagh et al., 1969), chorionic gonadotropin (Bahl, 1969), A myeoma globulin (Dawson and Clamp, 1968) and $\alpha_{2}$-macroglobulin (Dunn and Spiro, 1967). In the heteropolysaccharide chain, about four above units are linked to the so-called core (internal portion) containing mannose and $\mathrm{N}$-acetylglucosamine. The authors have considered that the average molecular weight of WKS is to be $3-4 \times 10$ " from its behavior on Sephadex G-50 and G-25. Assuming that the molecular weight of the carbohydrate chain of WKS is approximately $3 \times 10^{3}$, the chain is supposed to be composed of 4 residues of sialic acid, 8 residues of hexose and 8 residues of hexosamine from the sialic acid: hexose: hexosamine molar ratio of 1.00: 
2.18: 2.06. This suggests that about four oligosaccharide units containing sialic acid at the nonreducing end are present in the chain. The finding of Tetrasaccharide $\mathrm{S} 2$ containing the $\mathrm{N}$-acetylneuraminyl-galactosyl-N-acetylglucosamine unit in WKS supports the our presumption.

\section{ACKNOWLEDGEMENT}

The authors wish to thank Prof. M. Toyomizu for many helpful discussions and suggestions during this work, and they are also grateful to Dr. T. Taniguchi, Faculty of Fisheries, Nagasaki University, for a gift of a strain of Clostridium perfringens. Thanks are also due to the Fukuoka branch of Kyokuyo Co., Ltd. for supplying fresh nasal cartilage of a whale.

\section{REFERENCES}

Aminoff, D. 1961. Methods for the quantitative estimation of N-acetylneuraminic acid and their application to hydrolysates of sialomucoids. Biochem. J. 81: 384-392.

Bahl, 0. P. 1969. Human chorionic gonadotropin. II. Nature of the carbohydrate units. $\boldsymbol{J}$. Biol. Chem. 244: 575-583.

Bhavanandan, V. P. and K. Meyer 1967. Studies on keratosulfates. Methylation and partial acid hydrolysis of bovine corneal keratosulfate. J.Biol. Chem. 242: 4352-4359.

1968. Studies on keratosulfates. Methylation, desulfation and acid hydrolysis studies on old human rib cartilage keratosulfate. J. Biol. Chem. 243: 1052-1059.

Bray, B. A., R. Lieberman and K. Meyer 1967. Structure of human skeletal keratosulfate. The linkage region. J. Biol. Chem. 242: 3373-3380.

Callahan, J. W. and L. S. Wolfe 1970. Isolation and characterization of keratan sulfates from the liver of a patient with $\mathrm{G}_{\mathrm{M}} \mathrm{I}$ gangliosidosis type 1. Biochim. Biophys. Acta 215: 527-543.

Cassidy, J. T., G. W. Jourdian and S. Roseman 1965. The sialic acids. VI. Purification and properties of sialidase from Clostridium perfringens. J. Biol. Chem. 240: 3501-3506.

Dawson, G. and J. R. Clamp 1968. Investigations on the oligosaccharide units of an A myeloma globulin. Biochem. J. 107: 341-352.

Dische,Z. 1955. Cysteine-sulfuric acid reaction of hexoses. Methods of Biochemical Analysis 2: 327-328. Interscience publishers, Inc., New York.

Dunn, J. T. and R. G. Spiro 1967. The a,-macroglobulin of human plasma. II. Studies on the carbohydrate units. J. Biol. Chem. 242: 5556-5563.

Goldstein, I. J., G. W. Hay, B. A. Lewis and F. Smith 1965. Controlled degradation of polysaccharides by periodate oxidation, reduction and hydrolysis. Methods in Carbohydrate Chemistry 5: 361-370. Academic Press, New York.

Guthrie, R. D. 1962. Periodate oxidation. Determination of periodate. Methods in Carbohydrate Chemistry 1: 435-441. Academic Press, New York.

Hirano, S., P. Hoffman and K. Meyer 1961. The structure of keratosulfate of bovine cornea. J. Org. Chem. 26 : 5064-5069.

Kuhn, R. and H. Wiegandt 1963. Die Konstitution der Ganglio-N-tetraose und des Gangliosids $\mathrm{G}_{1}$. Chem. Ber. 96: 866-877.

MacFadyen, D. A. 1945. Estimation of formaldehyde in biological mixtures. J. Biol.Chem. $158: 107-133$.

Mathews, M. B. and J. A. Cifonelli 1965. Comparative biochemistry of keratosulfate. J. Biol. Chem. 240 : 4140-4145. 
Meyer, K., A. Linker, E. A. Davidson and B. Weissmann 1953. The mucopolysaccharides of bovine cornea. J.Biol. Chem. 205: 611-616.

Meyer, K., V. P. Bhavanandan, D. Yung, L. T. Lee and C. Howe 1967. The keratosulfatelike mucopolysaccharide of chick allantoic fluid. Proc. Natl.Acad. Sci. 58: 1655-1659.

Muramatsu, T. 1967. Purification and properties of $\alpha$-mannosidase from the liver of Charonia lampas. J. Biochem. 62: 487-491.

- 1968. N-Acetylhexosaminidases from a gastropod, Turbo cornutus. J. Biochem. 64 : 521 531.

Muramatsu, T. and F. Egami 1967. $\alpha$-Mannosidase and $\beta$-mannosidase from the liver of Turbo cornutus : purification, properties and application in carbohydrate research. $J$. Biochem. 62 : 700-709.

Nakagawa, H. 1971. Isolation of keratosulfate-like mucopolysaccharide containing a large amount of sialic acid from whale cartilage proteinpolysaccharide. Bull. Japan. Soc. Sci. Fisheries $37: 197-202$.

Nakagawa, H. and K. Satake 1971. Whale cartilage keratosulfate-1. Its fractionation and characterization. Bull. Japan. Soc. Sci. Fisheries 37:919-926.

Nakagawa, H., N. Enomoto and Y. Tomiyasu 1964. Identification of crystalline sialic acid obtained from nasal cartilage of a whale. Bull. Japan. Soc. Sci. Fisheries $30: 580-584$.

Neuberger, A., R. D. Marshall and A. Gottschalk 1966. Periodate oxidation of N-acetylneuraminic acid. Glycoproteins : their composition, structure and function. p. 176. Elsevier Publishing Co., Amsterdam.

Park, J. T. and M. J. Johnson 1949. A submicrodetermination of glucose. J. Biol. Chem. 181: $149-151$

Rafelson, M. E., Jr., M. Schneir and V. W. Wilson, Jr. 1966. Neuraminidases. The amino sugars IIB: 171-179. Academic Press, New York.

Reissig, J. L., J. L. Strominger and L. F. Leloir 1955. A modified colorimetric method for the estimation of N-acetylamino sugars. J. Biol. Chem. 217: 959-966.

Seno, N., K. Meyer, B. Anderson and P. Hoffman 1965. Variations in keratosu'fates. J. Biol. Chem. 240: 1005-1010.

Seno, N. and N. Toda 1970. The carbohydrate-peptide linkage region of keratan sulfate from whale cartilage. Biochim. Biophys. Acta 215: 544-546.

Spiro, R. G. 1964. Periodate oxidation of the glycoprotein fetuin. J.Biol. Chem. 239: 567573.

- 1970. Glycoproteins. Ann. Rev. Biochem. 39: 599-638.

Staub, A. M. 1965. Removal of proteins. Methods in Carbohydrate Chemistry 5:5-6. Academic Press, New York.

Suzuki, K., K. Suzuki and S. Kamoshita 1969. Chemical pathology of $\mathrm{G}_{M 1}$-gangliosidosis. J. Neuropathol. Exptl. Neurol. $28: 25-71$.

Svennerholm, L. 1956. The determination of hexosamines with special reference to nervous tissue. ActaSoc. Med. Upsaliensis $61: 287-306$.

Thompson, A. and M. L. Wolfrom 1963. Deacetylation. Methods in Carbohydrate Chemistry $2: 215-220$.

Toda, N. and N. Seno 1970. Sialic acid in the keratan sulfate fraction from whale cartilage. Biochim. Biophys. Acta 208: 227-235.

Trevelyan, W. E., D. P. Procter and J. S. Harrison 1950. Detection of sugars on paper chromatograms. Nature $166: 444-445$.

Wagh, P. V., I. Bornstein and R. J. Winzler 1969. The structure of a glycopeptide from human orosomucoid ( $\alpha_{1}$-acid glycoprotein). J. Biol. Chem. 244: 658-665.

Werner, I. and L. Odin 1952. On the presence of sialic acid in certain glycoproteins and in gangliosides. Acta Soc. Med. Upsaliensis 57: 230-241.

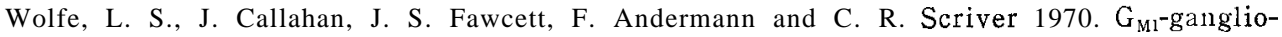
sidosis without chondrodystrophy or visceromegaly- $\beta$-galactosidase deficiency with gangliosidosis and the excessive excretion of a keratan sulfate. Neurology 20: 23-44.

Yemm, E. W. and A. J. Willis 1954. The estimation of carbohydrates in plant extracts by 
anthrone. Biochem. J. 57: 508-514.

Yemm, E. W. and E. C. Cocking 1955. The determination of amino-acids with ninhydrin. Analyst $80: 209-213$. 